\title{
Simulation and Experimental Investigation Quenching Behavior of Medium Carbon Steel in Water Based Multi Wall Carbon Nanotube Nanofluids
}

\author{
Ali Hussein Eissa ${ }^{1}$, Hala Salman Hasan ${ }^{2}$
}

\begin{abstract}
Authors Affiliations:
1) Mechanical Eng. Dept., Al-Nahrain University, Baghdad, Iraq. ali07813430945@gmail.co $\underline{\mathrm{m}}$

2*) Mechanical Eng. Dept., Al-Nahrain University, Baghdad, Iraq. halasalman2006@yahoo.co $\underline{\mathrm{m}}$

\section{Paper History:}

Received: $13^{\text {th }}$ Oct. 2019

Revised: 29 $9^{\text {th }}$ Dec. 2019

Accepted: $16^{\text {th }}$ March 2020

\begin{abstract}
Experiments were conducted to study the effect of quenching medium carbon steel in water-based MWCNTs nanofluids at $0.05 \%$ wt. concentration quenchant, a large cylindrical sample with $46 \mathrm{~mm}$ diameter and $40 \mathrm{~mm}$ length made from medium carbon steel used with three K-type thermocouples with a diameter of $1.5 \mathrm{~mm}$ inserted in three locations for sample (center of the sample, mid-point between center and surface and $1 \mathrm{~mm}$ from the surface). A timetemperature reading data system was used to read temperature history during cooling stage.

The same experiments were simulated using ANSYS Workbench with Thermal Transient Version 19, the cooling curves at three locations for the cylindrical steel sample calculated during quenching in MWCNTs nanofluids. Quench factor analysis was used to predict the hardness results from the calculated and measured cooling curves, and these results compared with the hardness test results conducted in the significant sample from the center to the surface. The results show excellent compatibility when compared between the hardness results from cooling curves, and it also shows a good agreement with the results of the hardness test, especially at the sample surface.
\end{abstract}

Keywords: MWCNTs Nanofluids, Quenching Process, Medium Carbon Steel.

\section{Introduction}

The quenching process remains one of the most important commonly used heat treatment processes in manufacturing to obtain the desired mechanical properties. It included a rapid cooling and heat extraction from the high-temperature part by quickly immersion in liquid, traditionally water, oil, brine, and polymer solution [1]. Many heat transfer mechanisms included at the solid-liquid interface (which might be involv a vapor film), it an expressed in terms of the effective heat transfer coefficient (h), which is a function to the part surface temperature [2].

It is often referring to as accelerating the transition from film boiling to nucleate boiling by increased cooling rate [3]. The modern researches in scientific institutions are studying a new type of cooling media with having high ability to transfer heat, which called nanofluids [4].

Nanofluids are a new kind of liquid engineering suspensions that have a higher capacity than conventional fluids to achieve the desired heat transfer characteristic. It is preparing from uniform added nanoparticles with size range $(1-100 \mathrm{~nm})$ having high thermal conductivity into base liquids such as water, ethylene glycol, or oil. These nanoparticles may be oxide ceramic nanoparticles such as $\left(\mathrm{Al}_{2} \mathrm{O}_{3}, \mathrm{SiO}_{2}, \mathrm{TiO}_{2}\right)$, metals nanoparticles $(\mathrm{Cu}, \mathrm{Au}, \mathrm{Ag})$, metal carbides $(\mathrm{SiC})$, and carbon nanotubes (CNT) can be added to the base fluids [5]. The term nanofluids was first defined by Choi in 1995 [6].

Quench Factor Analysis (QFA) is a mean for estimate hardness and stress with a known quench path and isothermal transformation kinetics during continuous cooling when metal part exposure to quenching process, had been proposed by Evancho and Staley [7]. QFA gives one number to describe the quenching power; Calculations of quench factors are easily accessible from the data acquisition (cooling curve) and the time-temperature transformation curve (T'T'T) of the alloy of interest [8].

Simulating a quenching process requires detailed knowledge of the heat transfer coefficients (htc) at the hot solid-liquid interface. The htc can be estimated experimentally using a small probe with a thermocouple inserted into it to recorded timetemperature data during quenching small probe to evaluate htc [9].

D. Ciloglu et al. in 2011 [10] researched to study the effect of nanofluids on the quenching properties. Probes made from brass with $20 \mathrm{~mm}$ diameter and 75 $\mathrm{mm}$ length quenched in water and water nanofluids various volume fraction $\mathrm{Al}_{2} \mathrm{O}_{3}, \mathrm{SiO}_{2}, \mathrm{TiO}_{2}$ and $\mathrm{CuO}$. The results revealed that the addition of nanoparticles to water enhances the cooling rate, which in turn prevents the growth of bubbles around the surface,

NJES is an open access Journal with ISSN 2521-9154 and eISSN 2521-9162

This work is licensed under a Creative Commons Attribution-NonCommercial 4.0 International License 
resulting in increased heat transfer and improving the quenching process. Also showed water-based, nanofluids were better than other quenchants used. Repeated the cooling process three times in the nanofluids led to the disappearance of the boiling phase of the film that was present in the first round during the quenching process.

K. Babu and T.S.Kumar in 2011[11] were studied the heat extraction properties during the quenching process by used water-based multi-wall carbon nanotube (MWCNT) nanofluids with and without surfactant as a cooling media. $304 \mathrm{~L}$ stainless steel cylindrical probes with $20 \mathrm{~mm}$ in diameter and 50 $\mathrm{mm}$ length quenched in distilled water and waterbased MWCNT nanofluids. They found that the maximum heat flux was highest by $37.5 \%$ during quenching in MWCNT nanofluids and increasing in cooling rate without surfactant when compared with distilled water, where the maximum heat flux was reduced by $24.9 \%$ during quenching in MWCNT nanofluids with a surfactant as compared with distilled water.

In another study conducted by $\mathrm{G}$. Ramesh and $\mathrm{K}$. Narayan in 2012 [12] to study the effects of nanofluids on quenching power during quenching process, were used an Inconel 600 probe with 12.5 diameter and 60 length and heated it to $850{ }^{\circ} \mathrm{C}$ then immersed quickly in a water-based nanofluids solution with AL nanoparticles of variable concentration from 0.005 vol. $\%$ to 0.5 vol. $\%$. The results of the experiments showed that the cooling rates increased when using nanofluids as quenchant comparing with water, the results also showed a decrease in the film boiling stage at a concentration of up to 0.1 vol. $\%$, while the film boiling stage was longer at a concentration of 0.5 vol. $\%$.

J. Daniel and et al. in 2016 [13] studied the effects of nanofluids as a cooling media to be a substitute for traditional cooling media used in quenching processes, such as oil, water, and other conventional. Nanoparticles were used $\mathrm{Al}_{2} \mathrm{O}_{3}$, graphite, and montmorillonite. It was noted that the cooling rates for graphite and montmorillonite were close to the oil, while $\mathrm{Al} 2 \mathrm{O} 3$ was the cooling rate higher than water. The concentrations used were (0.01\% wt., 0.05 $\%$ wt. and $0.1 \%$ wt.). The researcher concluded that the using of cooling media type depends on the type of application of the metal to be hardening. Where montmorillonite or graphite can be used instead of the oil due to its natural cooling during the quenched section, that leads to less cracking and distortion, and environmentally friendly. $\mathrm{Al}_{2} \mathrm{O}_{3}$ nanofluids also can be used when martensite is required, for instance, getting tool steel because of faster cooling.

The aim of this research is to study the effect of quenching medium carbon steel on water-based MWCNT nanofluids at $0.05 \%$ wt. concentrations experimentally with simulation of that process by studying its effect on the hardness values result from the center to the surface of the sample during quenching process.
In this research work, the large sample of medium carbon steel was used. The chemical composition of the material is carried out at the Institute of Specialist for Engineering Industries as shown in table 1.It can be classified as AISI 1050 medium carbon steel according to the standard chemical compositions shown in table 2:-

Table 1: Chemical composition for the large sample steel.

\begin{tabular}{|c|c|c|c|c|c|c|c|c|c|c|}
\hline Elements & IC & $\mathrm{Si}$ & Mn & $\mathrm{P}$ & $S$ & & Mo & $\mathrm{Ni}$ & & \\
\hline Wt. $\%$ & $\begin{array}{l}0 \\
\stackrel{t}{0}\end{array}$ & $\stackrel{0}{i}$ & $\stackrel{\circ}{\stackrel{0}{\Xi}}$ & $\begin{array}{l}\stackrel{\circ}{0} \\
\stackrel{0}{N}\end{array}$ & $\begin{array}{l}0 \\
\dot{\mathcal{U}} \\
\text { an }\end{array}$ & $\stackrel{\circ}{\vec{N}}$ & $\begin{array}{l}\stackrel{0}{\circ} \\
\stackrel{2}{\circ} \\
\stackrel{\infty}{0}\end{array}$ & $\stackrel{\circ}{\stackrel{0}{0}}$ & $\underset{\infty}{\stackrel{\infty}{\infty}}$ & Bal. \\
\hline
\end{tabular}

Table 2: Chemical composition for AISI 1050 medium carbon steel.

\begin{tabular}{|c|c|c|c|c|c|c|c|c|}
\hline $\begin{array}{c}\text { Eleme } \\
\text { nts }\end{array}$ & C & $\mathrm{Si}$ & $\mathrm{Mn}$ & $\mathrm{P}$ & $S$ & $\mathrm{Cr}$ & $\mathrm{Ni}$ & $\mathrm{Cu}$ \\
\hline Wt. $\%$ & 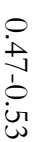 & 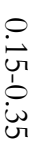 & $\begin{array}{l}0 \\
\hat{1} \\
\dot{1}\end{array}$ & $\begin{array}{l}1 \wedge \\
\stackrel{0}{0} \\
\dot{\omega}\end{array}$ & $\begin{array}{l}11 \\
0 \\
0 \\
\mathbf{w} \\
\text { un }\end{array}$ & $\begin{array}{l}11 \\
\stackrel{i}{N}\end{array}$ & $\stackrel{1}{1 \wedge}$ & $\begin{array}{l}11 \\
0 \\
i\end{array}$ \\
\hline
\end{tabular}

Quenching system used in the experiment to measure the time-temperature history inside the small probe consists of a data-acquisition system, tube furnace, a $1 \mathrm{~L}$ beaker containing the cooling media, and $\mathrm{K}$-type thermocouple. The surface of the probe is maintained by standard machining and grinding of the surface of the probe altogether to avoid any additional effect on the surface impurities that affect the thermocouple reading. The $1.5 \mathrm{~mm}$ diameter thermocouple was inserted into the cylindrical probe together with some fine graphite powder for better thermal contact.

A large sample of diameter $46 \mathrm{~mm}$ and $40 \mathrm{~mm}$ length used with three $\mathrm{K}$-type thermocouples with a diameter of $1.5 \mathrm{~mm}$ (center of the sample, mid-point between center and surface and $1 \mathrm{~mm}$ from the surface) inserted them into the sample holes as shown in Figure 1.The thermocouples are connected to the data logging system to record the temperature with time during the cooling process. Figure 2 shows the furnace and the thermocouple recorder system used in the experiment. Water-based Multi-Wall Carbon NanoTubes (MWCNTs) with concentrations (0.05 wt. \%) nanofluids prepared at the Nano Renewable Energy Research Center / Al-Nahrain University, MWCNTs were used as a nanomaterial and distilled water as a base fluid. The mixing process was performed using an Ultrasonic machine device with different preparation times as needed. 2 Litters nanofluids prepared is a proper amount to ensure that it does not change in its temperature due to the quench. The furnace switches to $850{ }^{\circ} \mathrm{C}$ and kept for 30 minutes before putting the large sample into the furnace for 60 minutes, which is enough to reach the required temperature $\left(850^{\circ} \mathrm{C}\right)$, then immersion the sample in the nanofluids. The cooling curves were then analyzed to predict the hardness of the sample.

\section{Experimental work}




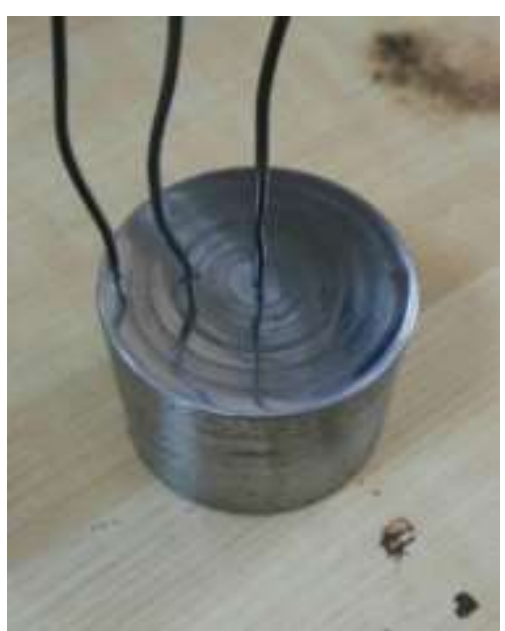

Figure 1: The steel sample with three locations in which the cooling curves were measured.

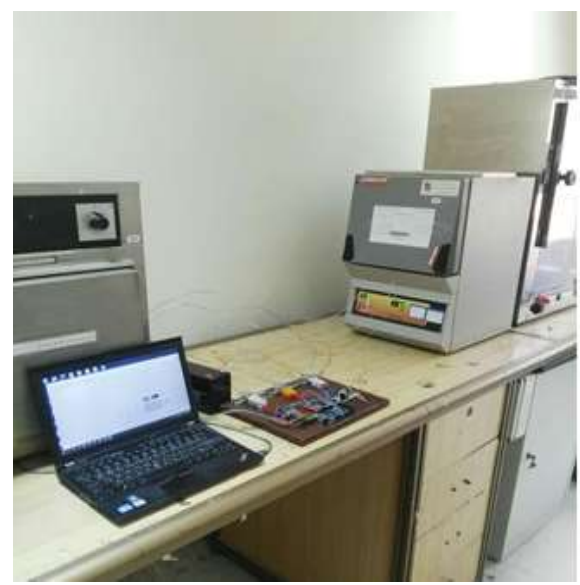

Figure 2: The furnace with the data logging system which used in the experiment

For hardness measurement and microstructure examinations after the quenching process, the large sample was prepared by using 400,600 and 1000 grinding papers. Then polishing was performed using diamond paste. Finally, the polished sample was cleaned by water and alcohol and then dried. The samples were etched using 3\% Nital solution and the microstructure examined using an optical microscope.

\section{Modeling with ANSYS 19}

In the present work, ANSYS Workbench software program with Thermal Transient field Version 19 was used to simulate the quenching process and investigate the cooling curves and cooling rates at three locations for the large steel sample. After drawing the geometric shape and define the properties of the large cylindrical sample, generating a mesh by using tetrahedral mesh type as shown in figure 3.Then input the boundary conditions, which including sample dimensions, initial temperature, quenchant temperature, thermal conductivity, and effective heat transfer coefficient (htc). Finally, running the program to obtained results. Heat transfer coefficient in the interface region between the solid surface and the quenchant very important in the simulation quenching process and its function to the surface temperature, which can be estimated using equations 1 and [2] by applied lumped capacity theory.

$$
\begin{gathered}
h=\frac{\rho V C_{p}(T) \frac{d T}{d t}}{A_{S}\left(T_{s}-T_{\infty}\right)} \\
C_{p}(T)=481.96+0.157 \mathrm{~T}-1.547 * 10^{-3} T^{2}+1.168 * \\
10^{-5} T^{3}-1.92 * 10^{-8} T^{4}+9.05 * 10^{-12} T^{5} \\
\mathrm{~J} \mathrm{Kg}^{-1} \mathrm{~K}^{-1}
\end{gathered}
$$

Where $C_{p}$ is the specific heat capacity at constant pressure, $V=6.14 * 10^{-8} \mathrm{~m}^{3}$ and $A_{s}=9.82 * 10^{-5}$ $\mathrm{m}^{2}$ the sample volume and surface area respectively, $\varrho=\vee \wedge \circ \wedge \mathrm{Kg} . \mathrm{m}^{-3}$ the density which is assumed to be constant, $T_{s}=850^{\circ} \mathrm{C}$ and $T_{\infty}=40^{\circ} \mathrm{C}$ surface temperature and quenchant temperature respectively and $\frac{d T}{d t}$ the instantaneous cooling rate, all these parameters for small probe.

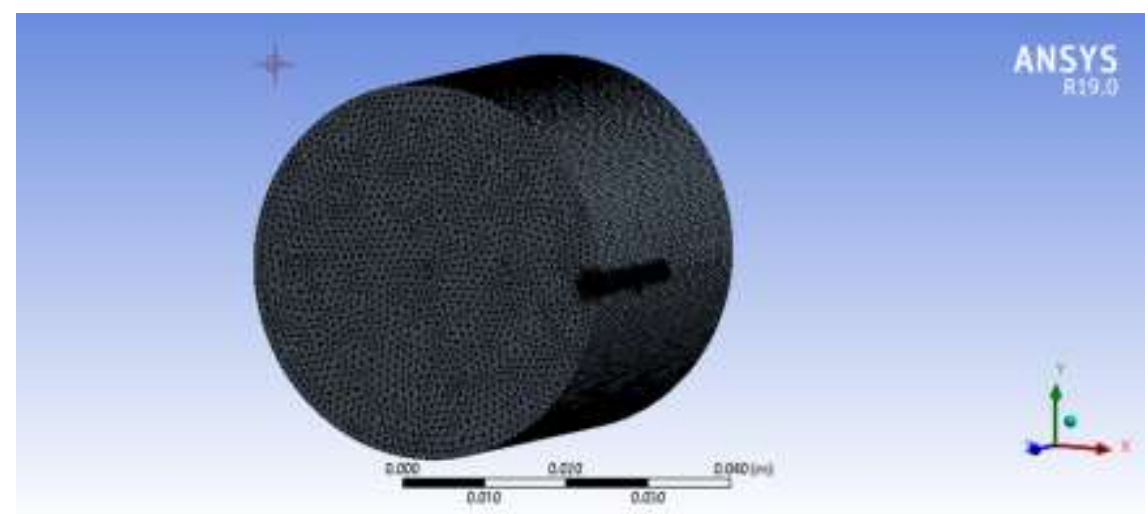

Figure 3: Mesh generated for cylindrical steel sample in ANSYS 19.

\section{Data Analysis, Results and Discussion}

The small probe with diameter $2.5 \mathrm{~mm}$ and $13 \mathrm{~mm}$ length quenched in water-based MWCNT $(0.05 \%$ wt.) nanofluids. The time-temperature data were used to evaluate the cooling rate, as shown in figure 4 . This cooling rate was used as an input to estimate the equation for an effective heat transfer coefficient at the solid-quenchant interface used in the simulation. Figure 5 illustrates the effective heat transfer coefficient dependent on the surface temperature. 


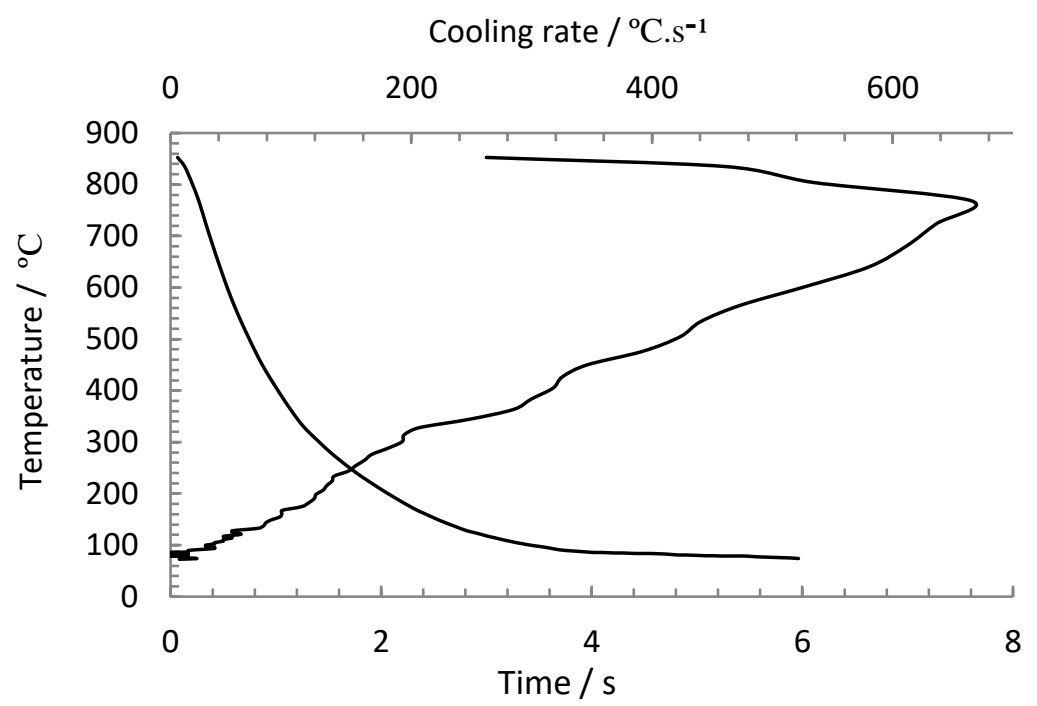

Figure 4: Cooling curve and derived cooling rate for small probe quenched in water based MWCNT (0.05\% wt.) nanofluids.

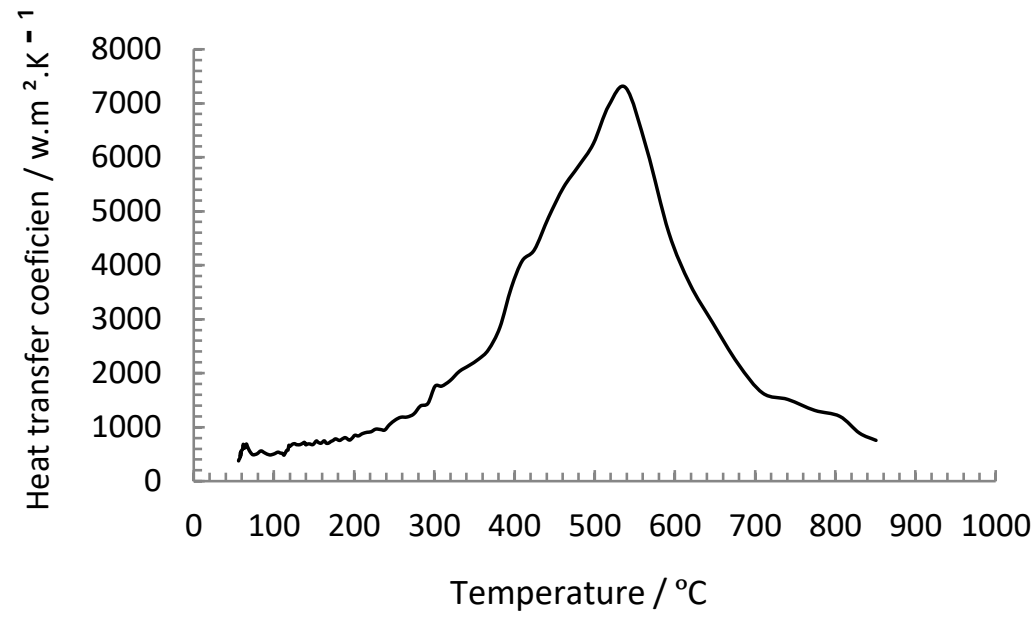

Figure 5: Heat transfer coefficient as a function of surface temperature during quenching the probe in water based MWCNT (0.05\% wt.) nanofluids.

Figures 6 showed the cooling curves and the derived cooling rates curves were calculated at three locations for the large steel sample during the quenching process in water-based MWCNT $(0.05 \%$ wt.) nanofluids at $45{ }^{\circ} \mathrm{C}$. Figures 7 illustrated the cooling curves and derived cooling rates curves calculated at three locations for the large steel sample during transient thermal simulation in the ANSYS program for the quenching process in water-based MWCNT $\left(0.05 \%\right.$ wt.) nanofluids at $45^{\circ} \mathrm{C}$. The temperature gradient from the surface to the center in a section of the steel sample in thermal transient simulation during the quenching process, as shown in figure 8 . The cooling curves and cooling rates obtained from ANSYS program and the experimental, demonstrate excellent compatibility when compared between them.
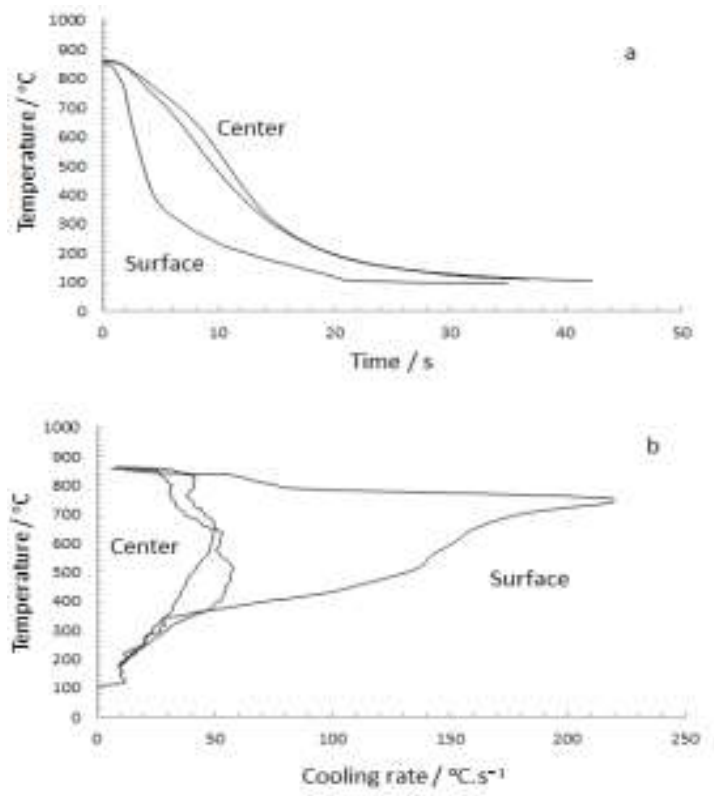
Figure 6 : Experimentally measured (a) cooling curves, (b) cooling rates curves for sample to three locations ( center-midpoint between center and surface- surface) during quenching in water based MWCNT (0.05\% wt.) nanofluids at $45^{\circ} \mathrm{C}$.
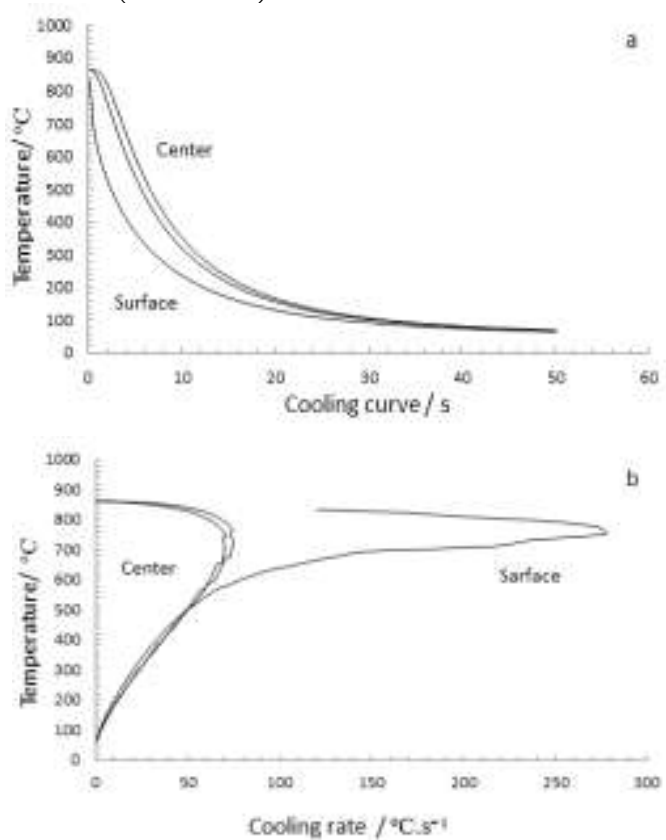

Figure 7: Calculated (a) cooling curves, (b) cooling rates from Ansys program for case study sample to three locations (center-midpoint between center and surface- surface) during quenching in water based MWCNT $(0.05 \%$ wt.) nanofluids.
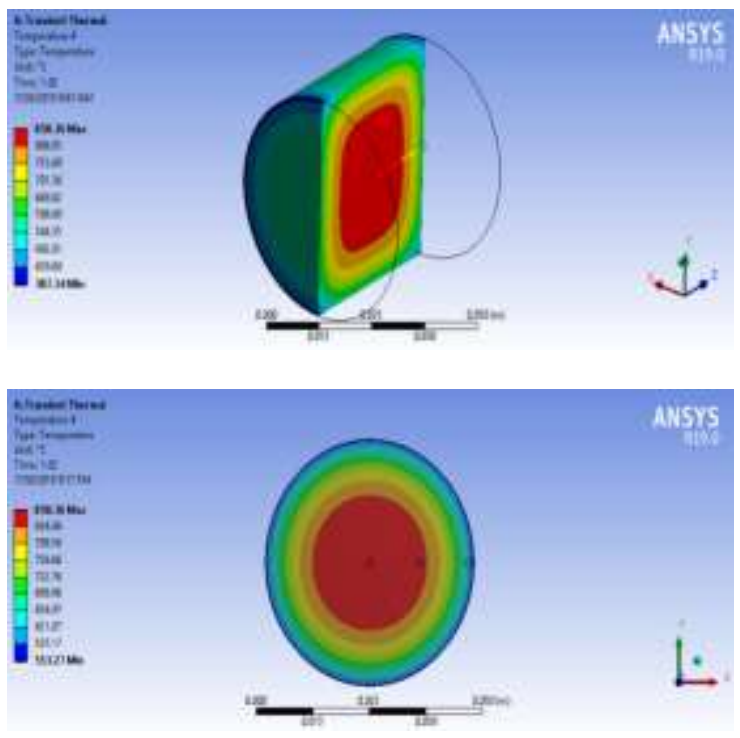

(a)

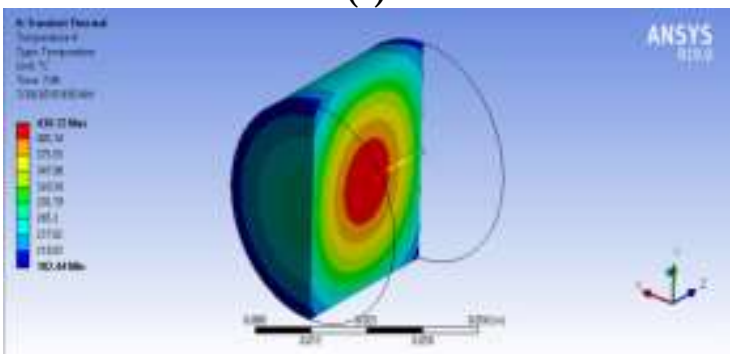

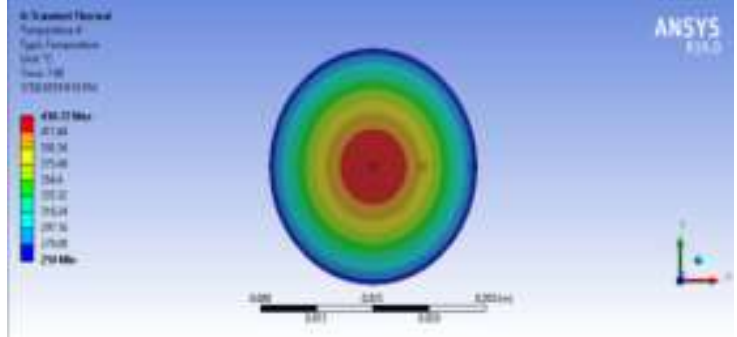

(b)

Figure 8: Temperature gradient from the surface to the center (a) after 1 second, (b) after 8 second, in section of the steel sample in thermal transient simulation for quenching process in a water-based MWCNT (0.05\% wt.) nanofluids.

The Cooling information can be used to predict variance in hardness because, in the quench factor analysis, there is a relationship between cooling curve and hardness property. Ivancho and Staly [15] originally proposed the quenching factor analysis. However, the variation of the value of hardness expressed in terms of the quench factor $\mathrm{Q}$ in the following equation [2]:

$$
H_{p}=H_{\text {min }}+\left(H_{\max }-H_{\min }\right) \exp \left(K_{1} Q\right)
$$

Where; $H_{p}=$ represents the expected hardness $H_{\max }$ and $H_{\text {min }}=$ represent the maximum and minimum hardness of steel, respectively. $K_{1}=$ the constant represents the natural logarithm of the volume fraction of transformation, usually $\ln 0.995=$ 0.00501, $Q=$ the cumulative quench factor over the entire transformation range between $A r_{3}$ and $M s$ [7]

$$
Q=\sum_{T=M_{S}}^{T=A_{r 3}} \frac{\Delta t}{t c}
$$

$\Delta \mathrm{t}$ represents the time step used in data acquisition and describes the locus of the critical time values as a function of temperature forms the TTT curve of the steel used. To knowing the measured maximum and minimum hardness for steel used. For this purpose, two small samples prepared and heating to $850^{\circ} \mathrm{C}$, the first quenched in brine quenchant with agitation to obtained maximum hardness and martensitic structure. The second sample cooled slowly by remained inside the furnace to obtained minimum hardness and pearlite structure. The maximum and minimum Vickers hardness was 713 $\mathrm{HV}$ and $175 \mathrm{HV}$, respectively.

Table 3 shows a good agreement between both the prediction hardness values from calculated and measured cooling curves by analyzing the quench factor and the experimental hardness values in the sample, especially the surface. However, the difference between hardness values increases as it approaches the center of the sample. The varieties in values between calculated and measure hardness is due to an error rate in the hardness values calculated when using the quenching factor analysis, which includes the error in thermal conductivity, the specific heat capacity of the steel, and the heat transfer coefficient calculations. Also, the thermal conductivity is a function of temperature and phase. Therefore it is difficult are precisely calculated when a 
phase change occurs, so the hardness results calculated by the quenching factor were more accurate in the surface area of the sample where the presence of martensitic structure.

Figure 9 illustrates the examination microstructure results of the large sample quenched in water-based MWCNT $(0.05 \%$ wt.) nanofluids for three regions (center, a midpoint between center and surface, surface)

Table 3: QF and hardness values in three locations for sample

\begin{tabular}{|c|c|c|c|c|c|c|}
\hline & \multicolumn{2}{|r|}{ Center } & \multicolumn{2}{|r|}{ Middle } & \multicolumn{2}{|c|}{$\begin{array}{c}1 \mathrm{~mm} \text { from } \\
\text { Surface }\end{array}$} \\
\hline & QF & Hardness & QF & Hardness & QF & Hardness \\
\hline $\begin{array}{l}\text { Prediction } \\
\text { from } \\
\text { calculated } \\
\text { cooling } \\
\text { curve } \\
\end{array}$ & $\wedge$ & $T V T$ & 7,0 & 711 & r & VIT \\
\hline $\begin{array}{l}\text { Prediction } \\
\text { from } \\
\text { measured } \\
\text { cooling } \\
\text { curve }\end{array}$ & 1,0 & $7 V 1$ & 7,1 & $7 \wedge \varepsilon$ & 1,0 & $\vee \wedge$ \\
\hline $\begin{array}{l}\text { Measured } \\
\text { hardness }\end{array}$ & & $\leqslant \leqslant 9$ & & 071 & & V)T \\
\hline
\end{tabular}

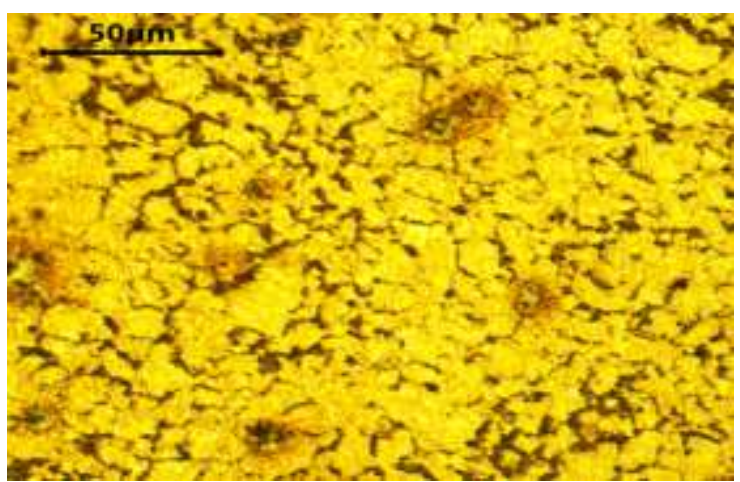

(a) $\leqslant \leqslant 9 \mathrm{HV}$

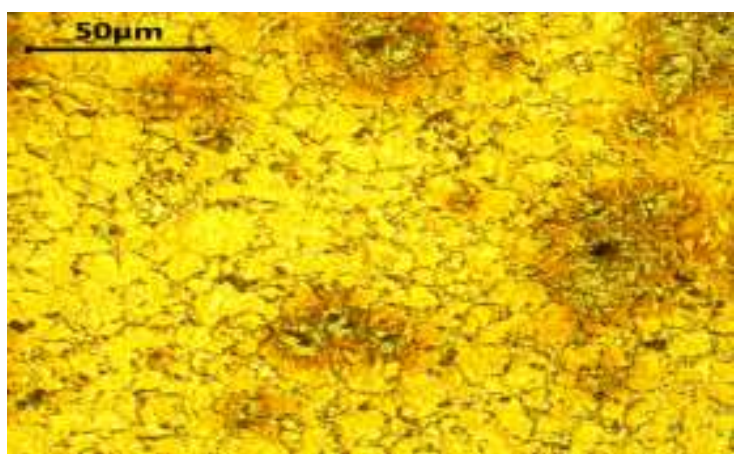

(b) $071 \mathrm{HV}$

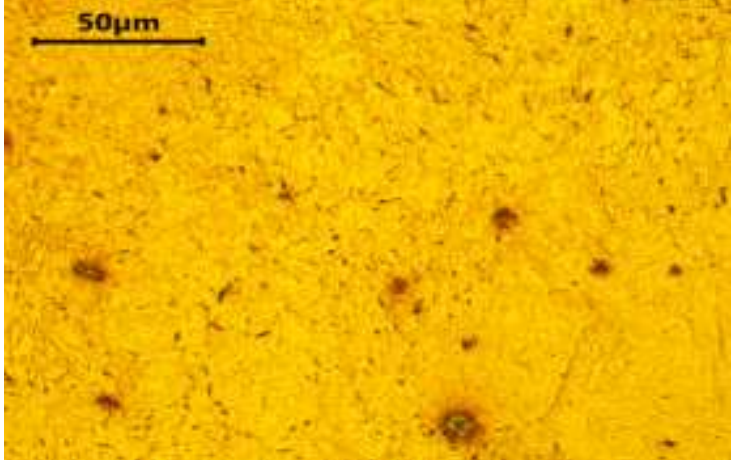

(c) $716 \mathrm{HV}$

Figure 8: microstructure for three locations at steel sample (a) center, (b) midpoint between center and surface, $(c)$ surface.

\section{Conclusion}

1-The ANSYS simulation of the quenching process of the large steel sample in nanofluids gave very close results with experimental results in terms of the distribution of sample predicted hardness by using the quench factor calculations.

$r$-The quench factor technique combined with cooling curves can enable the estimation of hardness variation as a function of distance.

$r$-The predicted hardness values were achieved by both calculated and measured cooling curves for three regions compared to the hardness test, there is good agreement especially in the sample surface.

4-The microstructure varies with the distance from the center to the sample surface. Where the martensitic structure in the sample surface had the highest hardness value $716 \mathrm{HV}$ when it quenched in a water-based MWCNT (0.05 wt. \%) nanofluids.

\section{Reference}

[1] Hasan, Hala S., Reham H. Khaleefah, and Raad D. Salman. "Effect of Agitation, Temperature, and Quenching Medium on Cooling Curve and cooling rate for Steels." AlNahrain Journal for Engineering Sciences 21.4 (2018): 473-478.

[2] Hasan, H. S., et al. "Heat transfer coefficients during quenching of steels." Heat and mass transfer 47.3 (2011): 315-321.

[3] Chinchole, A. S., P. P. Kulkarni, and A. K. Nayak. "Experimental investigation of quenching behavior of heated zircaloy rod in accidental condition of nuclear reactor with water and water based nanofluids." Наносистемы: физика, химия, математика 7.3 (2016).

[4] Raja, M., et al. "Review on nanofluids characterization, heat transfer characteristics and applications." Renewable and sustainable energy reviews 64 (2016): 163-173.

[5] Duangthongsuk, Weerapun, and Somchai Wongwises. "Measurement of temperaturedependent thermal conductivity and viscosity of TiO2-water nanofluids." Experimental thermal and fluid science 33.4 (2009): 706-714.

[6] Choi, Stephen US, and Jeffrey A. Eastman. Enhancing thermal conductivity of fluids with 
nanoparticles. No. ANL/MSD/CP-84938; CONF-951135-29. Argonne National Lab., IL (United States), 1995.

[7] Staley, J. T. "Quench factor analysis of aluminium alloys." Materials Science and Technology 3.11 (1987): 923-935.

[8] MacKenzie, D. S., and J. W. Newkirk. "Quench Factor Analysis for Heat Treatment Optimization of 7XXX Aluminum Alloys." International Federation of Heat Treatment and Surface Engineering Conference. 2001.

[9] R. N. Penha, G.Sanchez Sarmiento and G. E. Totten "Simulation of Heat Transfer PROPERTIES and Thermal Residual Stress From Quenching Studies "Minerva, 2(2): p.p. 165-172.

[10] Ciloglu, Dogan, and Abdurrahim Bolukbasi. "The quenching behavior of aqueous nanofluids around rods with high temperature." Nuclear Engineering and Design 241.7 (2011): 2519-2527.

[11] Babu, K., and T. S. Prasanna Kumar. "Estimation and analysis of surface heat flux during quenching in CNT nanofluids." Journal of Heat Transfer 133.7 (2011).

[12] Ramesh, G., and K. Prabhu. "Effect of Addition of Aluminum Nanoparticles on Cooling Performance and Quench Severity of Water during Immersion Quenching." Nanofluids. ASTM International, 2012.

[13] J. Daniel ,T.Ivana, A. Lerma and F. S. Delgado, "nanofluids as quenching media", Department of Engineering, University of Monterrey, San Pedro Garza García, Mexico.

https://www.academia.edu/28416160/Nanofluids a s quenching media. 